\title{
Molecular dynamics in polyurethane foams chemically reinforced with POSS
}

\author{
Konstantinos N. Raftopoulos ${ }^{1}$ - Joanna Pagacz ${ }^{2}$ • Jan Ozimek ${ }^{1}$. \\ Stefanos Koutsoumpis ${ }^{3,4}$. Sławomir Michałowski ${ }^{1}$ - Edyta Hebda ${ }^{1}$. \\ Jan Pielichowski ${ }^{1} \cdot$ Krzysztof Pielichowski $^{1}$
}

Received: 12 April 2018 / Revised: 29 August 2018 / Accepted: 14 September 2018 /

Published online: 18 September 2018

(c) The Author(s) 2018

\begin{abstract}
In this work, we report on the thermal and thermomechanical properties of rigid PU foams modified with POSS moieties, paying special attention to molecular dynamics of these systems. 1,2-Propanediolisobutyl POSS (PHI-POSS) are used as pendent groups and octa(3-hydroxy-3-methylbutyldimethylsiloxy) POSS (OCTA-POSS) serve as chemical crosslinks. DSC reveals an initial slowing down of the segmental dynamics for small loadings (5 wt $\%$ ) of both POSS moieties, followed by an acceleration, probably due to changes in the topology of the PU network and the morphology of the foam. A low-temperature mechanical relaxation is observed by DMA and is attributed tentatively to a local $\beta$ relaxation, much similar to that observed in hyperbranched polyurethanes.
\end{abstract}

Keywords Polyurethane foams $\cdot$ POSS $\cdot$ Molecular dynamics $\cdot$ DMA

\section{Introduction}

Rigid polyurethane foams are used extensively as insulation in many applications such as walls and roofs [1, 2]; however, unmodified PU foams are highly cellular materials which are easily ignitable and highly flammable. This flammability is a

Konstantinos N. Raftopoulos

raftopoulos@chemia.pk.edu.pl

1 Department of Chemistry and Technology of Polymers, Cracow University of Technology, ul. Warszawska 24, 31-155 Kraków, Poland

2 Institute of Ceramics and Building Materials, Ceramic and Concrete Division in Warsaw, ul. Postępu 9, 02-676 Warsaw, Poland

3 Department of Physics, National Technical University of Athens, Iroon Polytechneiou 9, Zografou Campus, 15780 Athens, Greece

4 Present Address: RNanolab, School of Chemical Engineering, National Technical University of Athens, Iroon Polytechneiou 9, Zografou Campus, 15780 Athens, Greece 
factor which limits their broader use [3] and therefore gives rise to a demand for fire-retarding additives. Alongside traditional substances, polyhedral oligomeric silsesquioxanes (POSS) have also been tested as fire retardant additives in many polymeric systems. POSS are unique organic-inorganic nanobuilding blocks, with a rigid siliceous core with silicon $(\mathrm{Si})$ atoms on the vertices and oxygen $(\mathrm{O})$ atoms on the edges. Organic groups are attached on the Si atoms which allow the cage-like cores to be directly bound to polymer chains, via covalent linkage [4-7]. These siliceous cages have sizes of 1-3 $\mathrm{nm}$ and can be considered to be the smallest possible particles of silica.

In our previous work, we have incorporated these nanomoieties in a model rigid polyurethane matrix, with the intention to improve its thermostability and fire resistance. Two binding modes have been used: (1) a moiety with one functional vertex group possessing two $\mathrm{OH}$ groups was pendent on the polyurethane chains (1,2-propanediolisobutyl POSS, PHI-POSS), and (2) a moiety with all its eight vertex groups possessing an $\mathrm{OH}$ group acted as a crosslink (octa(3-hydroxy-3-methylbutyldimethylsiloxy) POSS, OCTA-POSS). The synthesis of these systems as well as their structure, morphology, and mechanical properties was described in [8], while their thermal stability was studied in detail in [9]. Both POSS moieties reacted very well with the polyurethane components but the pendent one suppressed the formation of hydrogen bonds between urethane segments and thus presumably the microphase separation. The mechanical modulus increased with addition of both types of particles as a result of reinforcement and of changes in the cell structure. SEM and XRD revealed that POSS tend to form extended crystals that reside either in the bulk (PHI-POSS) or the walls (OCTA-POSS) of the foam. Although none of the moieties improved considerably the thermal stability, an analysis of the gaseous products revealed that POSS changes the degradation mechanism and also affected the formation of char. The changes were also related to the geometry of the materials, i.e. the size and shape of open cells as well as the percentage of open cells.

What is still missing from this line of work is a good understanding of the molecular mobility in these systems and its relationship with their physicochemical properties. Moreover, a study of molecular mobility in rigid foams has a broader interest as such data are scarce in the literature and definitely not very well understood. For example, Hatakeyama et al. [10] in a rigid polyol system observed significant differences in the glass transition temperatures as measured by differential scanning calorimetry (DSC) and thermomechanical analysis (TMA). The same authors later extended their measuring range to lower temperatures and detected a second glass transition at approximately $-50{ }^{\circ} \mathrm{C}$ and attributed it to the castor oil, which was one of the components they used [11]. This is to the best of our knowledge, the only work that reports two distinct glass transitions steps. Thirumal et al. [12], in a system similar to ours, observed by DSC a glass transition step around $100{ }^{\circ} \mathrm{C}$ whose temperature increased with decreasing density of the foam. Generally, in rigid PU foams glass calorimetric transition temperatures are reported at temperatures ranging from - 10 to $150{ }^{\circ} \mathrm{C}$ [13-17]. In DMA experiments, a drop in mechanical modulus accompanied by a complex broad peak in tan $\delta$ appears only after $100{ }^{\circ} \mathrm{C}$ $[14,18]$. Narine et al. [18] observed as well a small tan $\delta$ peak at temperatures around $-70{ }^{\circ} \mathrm{C}$ which they named $\beta$ relaxation and associated it with rotation of 
backbone chain motion of the short groups in the chain of the fatty acids used in their formulation.

In the current article, we perform a short study of molecular dynamics, using dynamic mechanical analysis (DMA) and differential scanning calorimetry (DSC). We study in detail how POSS affect the molecular mobility in rigid polyurethane foams, in light also of the results of our previous work on the morphology of those particular systems. Furthermore, we crossevaluate our results with the literature trying to shed more light on the complex field of molecular dynamics in rigid PU foams.

\section{Experimental}

\section{Materials}

Polyurethane foams were synthesized using (1) a sorbitol based polyether polyol, and (2) polymeric 4,4'-diphenylmethane diisocyanate (polymeric MDI). A nonhydrolyzable silicone surfactant and a tertiary amine catalyst were applied as auxiliary agents. As reactive nanoadditives 1,2-propanediolisobutyl POSS and octa (3-hydroxy-3-methylbutyldimethylsiloxy) POSS were used (Hybrid Plastics, USA). Details on the reactants are given in [8].

\section{Synthesis}

The polyurethane foams were obtained in a three-step process, in detail described in our previous work [8, 9, 19]. Briefly, dispersions of different POSS in THF were introduced to polyol under ultrasonic conditions, and afterwards, the catalyst, water, and surfactant were added in order to prepare the polyol premix (component A). In the next step, n-pentane as a physical blowing agent was added to component A. Then, the component A and B [polymeric 4,4'-diphenylmethane diisocyanate (PMDI)] were mixed together and stirred for $15 \mathrm{~s}$. Finally, the prepared mixtures were dropped into a Teflon open mould. All the experiments were performed at ambient temperature (ca. $20^{\circ} \mathrm{C}$ ).

\section{Differential scanning calorimetry-DSC}

DSC curves were recorded with a PerkinElmer Pyris 6 calorimeter, cooled with liquid nitrogen, and purged with nitrogen gas. In order to increase the mass of the samples that could be fitted inside standard aluminium crucibles, foam samples were immersed in liquid nitrogen and crushed to powder. Samples of 4-7 mg were used for the measurement. A first heating run at $10 \mathrm{~K} / \mathrm{min}$ to $250{ }^{\circ} \mathrm{C}$ was used to remove water and erase the thermal history. During this run, a water evaporation peak was recorded, but no peaks related to microphase mixing. A cooling run down to $-100{ }^{\circ} \mathrm{C}$ at $10 \mathrm{~K} / \mathrm{min}$ followed, and a final heating at $10 \mathrm{~K} / \mathrm{min}$ up to $250{ }^{\circ} \mathrm{C}$ 
was used for evaluation. Glass transition temperatures were calculated as midpoint values.

\section{Dynamic mechanical analysis-DMA}

DMA thermograms were recorded with a Netzsch 242C dynamic mechanical analyser in compression mode. The compression was applied along the foaming direction on samples of $5 \mathrm{~mm}$ thickness and $10 \times 10 \mathrm{~mm}^{2}$ cross section. The amplitude of the oscillation was $25 \mu \mathrm{m}$. Three rather low frequencies were used $(1,2$, and $10 \mathrm{~Hz})$ because during test measurements we observed that higher frequencies tended to fracture the rigid foams. Temperature range was -105 to $105^{\circ} \mathrm{C}$ at a rate of $2 \mathrm{~K} /$ min. Please note though that in the region around $50{ }^{\circ} \mathrm{C}$, the samples collapsed even at the very low stresses we applied.

\section{Results and discussion}

\section{Differential scanning calorimetry (DSC) results}

The main event in the DSC curves is a very broad glass transition step around $140{ }^{\circ} \mathrm{C}$ (Fig. 1). As we mentioned also in the introduction, several authors have

Fig. 1 Normalized DSC curves recorded with the PU matrix and the hybrid foams

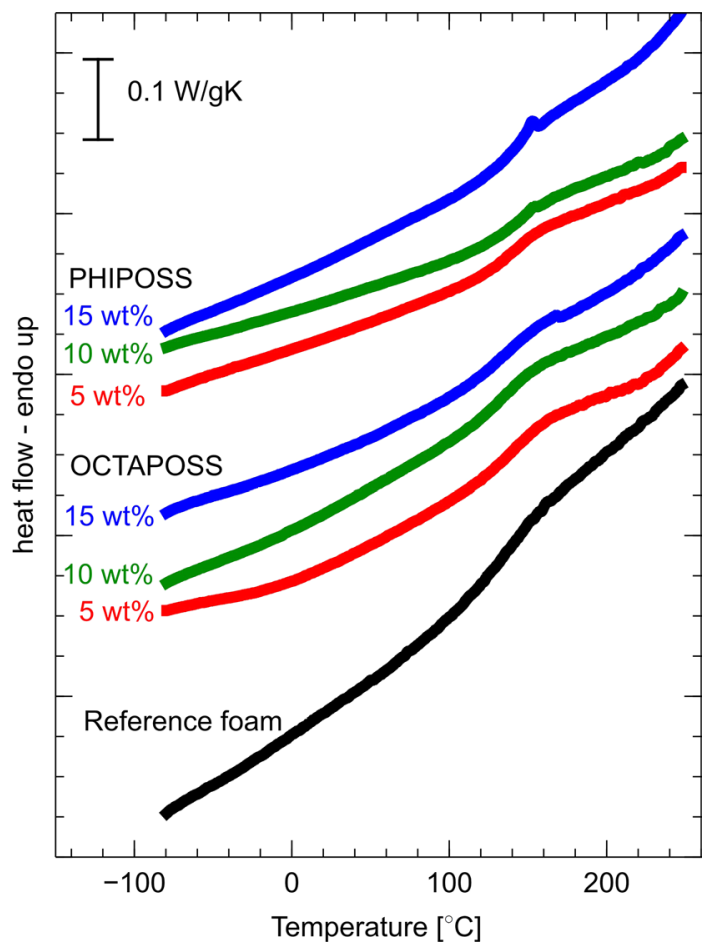


detected a glass transition step at the same region in rigid PU foams $[11,20]$. Small loadings (5 wt\%) of both POSS species enhance the midpoint $T_{\mathrm{g}}$ (Table 1) indicating a deceleration of the segmental dynamics, similar to what has been observed in elastomeric systems with the same particles [21-23]. Here, we may attribute this effect to immobilization of PU chain segments on the bulky POSS particles. On the contrary, upon further loading, the $T_{\mathrm{g}}$ decreases for both types of silsesquioxane additives (Table 1), denoting an acceleration of dynamics. The same trend has been also observed in very similar systems but with disilanolisobutyl POSS incorporated along the chain contour, being actually part of the main chain [9].

There are four possible reasons for that, explaining also the counterintuitive observation that a high amount of a crosslinking moiety can accelerate dynamics: (1) The PU matrix itself is highly crosslinked and an excess of POSS particles may actually disrupt this crosslinking, even if it is multifunctional [22]. (2) Possible aggregation of POSS at high loadings hinders the interaction with the matrix. (3) It has been observed that during the synthesis of the foams the viscosity of the polyol component increased with addition of the POSS diols [8, 19], thus a reduction in the efficiency of the reaction may have occurred, and thus a looser, more mobile network may have formed. (iv) The organic groups of the POSS moieties may be more flexible than the hard macromolecular segments of the PU-foamed matrix.

We now turn our attention to secondary features of the DSC curves. For the OCTA-POSS hybrids, a wide endothermic event starts at $0{ }^{\circ} \mathrm{C}$ and is superimposed as a shoulder on the low-temperature side of the glass transition step. We may assume that it is related to the relaxation of POSS-crosslinked regions inside the foam, thus supporting the assumption that POSS actually have faster dynamics than the polymeric matrix.

Interestingly, although OCTA-POSS crystals were detected by wide-angle $\mathrm{X}$-ray diffraction already at $10 \mathrm{wt} \%$ (WAXD) [8], only a very weak narrow endothermic peak is observed for $15 \mathrm{wt} \%$ loading and around $150{ }^{\circ} \mathrm{C}$ in the studied region, presumably because of the lower sensitivity of DSC with respect to crystallinity. On the other hand, melting peaks of PHI-POSS are detected at $153{ }^{\circ} \mathrm{C}$ for all the hybrids which contain it. This is in agreement with WAXD studies that indicate more intense crystallinity for this kind of silsesquioxane [8].

Table 1 Midpoint glass transition temperatures $T_{\mathrm{g}}$ recorded with the neat PU foam and the hybrids and peak temperature $T_{\beta}$ of the low-temperature relaxation recorded by DMA at $5 \mathrm{~Hz}$

\begin{tabular}{|c|c|c|c|c|}
\hline \multirow{2}{*}{$\begin{array}{l}\text { Sample } \\
\text { (POSS wt } \%)\end{array}$} & \multicolumn{2}{|l|}{$T_{\mathrm{g}}\left({ }^{\circ} \mathrm{C}\right)-\mathrm{DSC}$} & \multicolumn{2}{|c|}{$T_{\beta}\left({ }^{\circ} \mathrm{C}\right)-\operatorname{DMA}(5 \mathrm{~Hz})$} \\
\hline & OCTA-POSS & PHI-POSS & OCTA-POSS & PHI-POSS \\
\hline 0 & 138 & & -39 & \\
\hline 5 & 147 & 145 & -50 & -25 \\
\hline 10 & 140 & 143 & -44 & -50 \\
\hline 15 & 132 & 136 & -44 & -45 \\
\hline
\end{tabular}




\section{Dynamic mechanical analysis (DMA) results}

The tan $\delta$ profiles, for all PU/POSS materials, show three distinct regions in the studied temperature range (Figs. 2, 3). A weak peak at temperatures below $-30{ }^{\circ} \mathrm{C}$, a prominent peak in the vicinity of $80{ }^{\circ} \mathrm{C}$, and a shoulder on the latter around $0{ }^{\circ} \mathrm{C}$

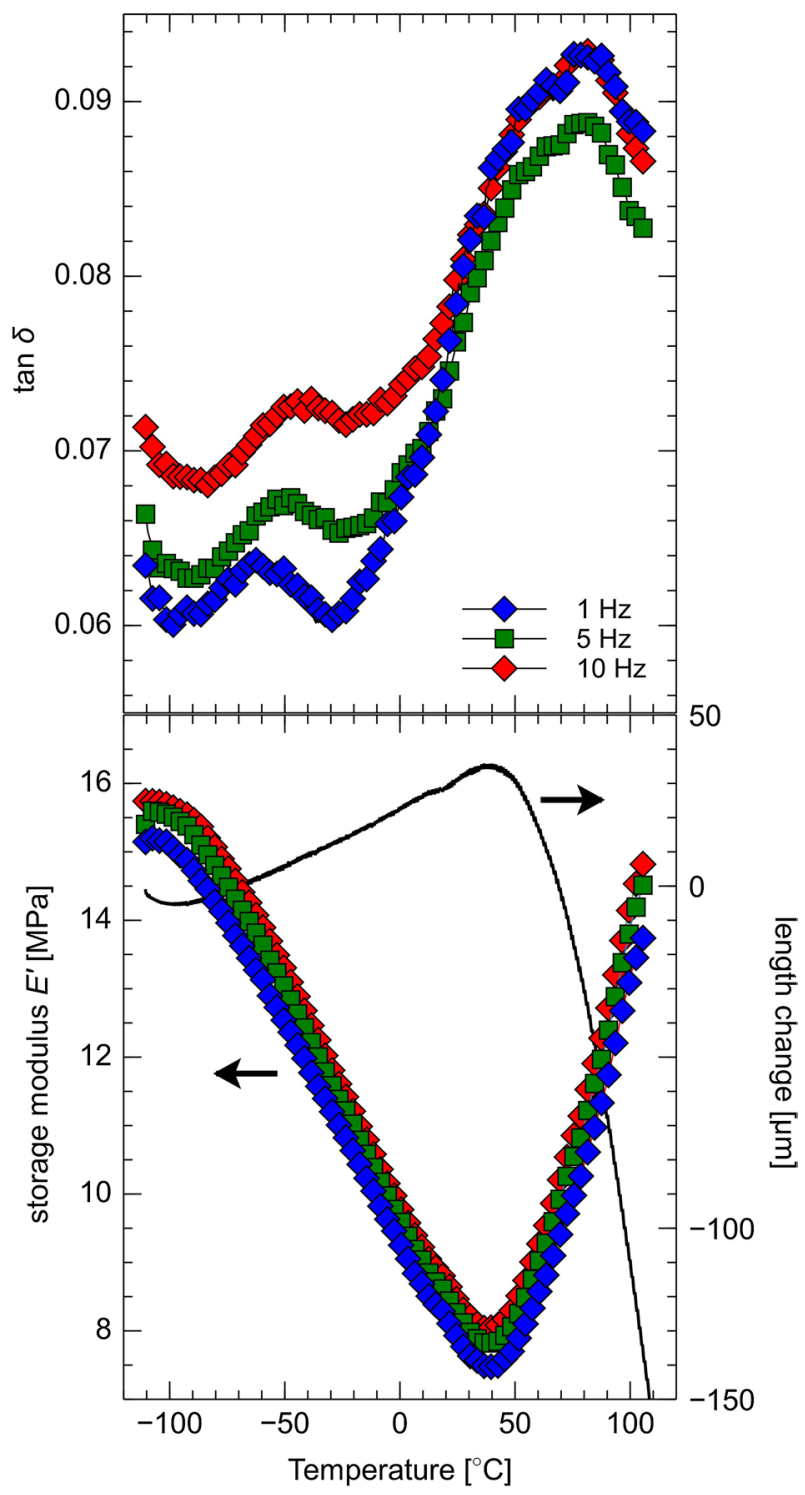

Fig. 2 Representative $\tan \delta$ and $E^{\prime}$ curves recorded with the rigid PU foam with $10 \mathrm{wt} \%$ PHI-POSS. For clarity, only every third experimental point is plotted. The length change of the sample as a function of temperature is included for comparison 
Fig. $3 \tan \delta$ thermograms recorded at $5 \mathrm{~Hz}$ with the rigid PU foam matrix and the hybrid foams with PHI-POSS (top) and OCTA-POSS (bottom). For clarity, only every third experimental point is plotted

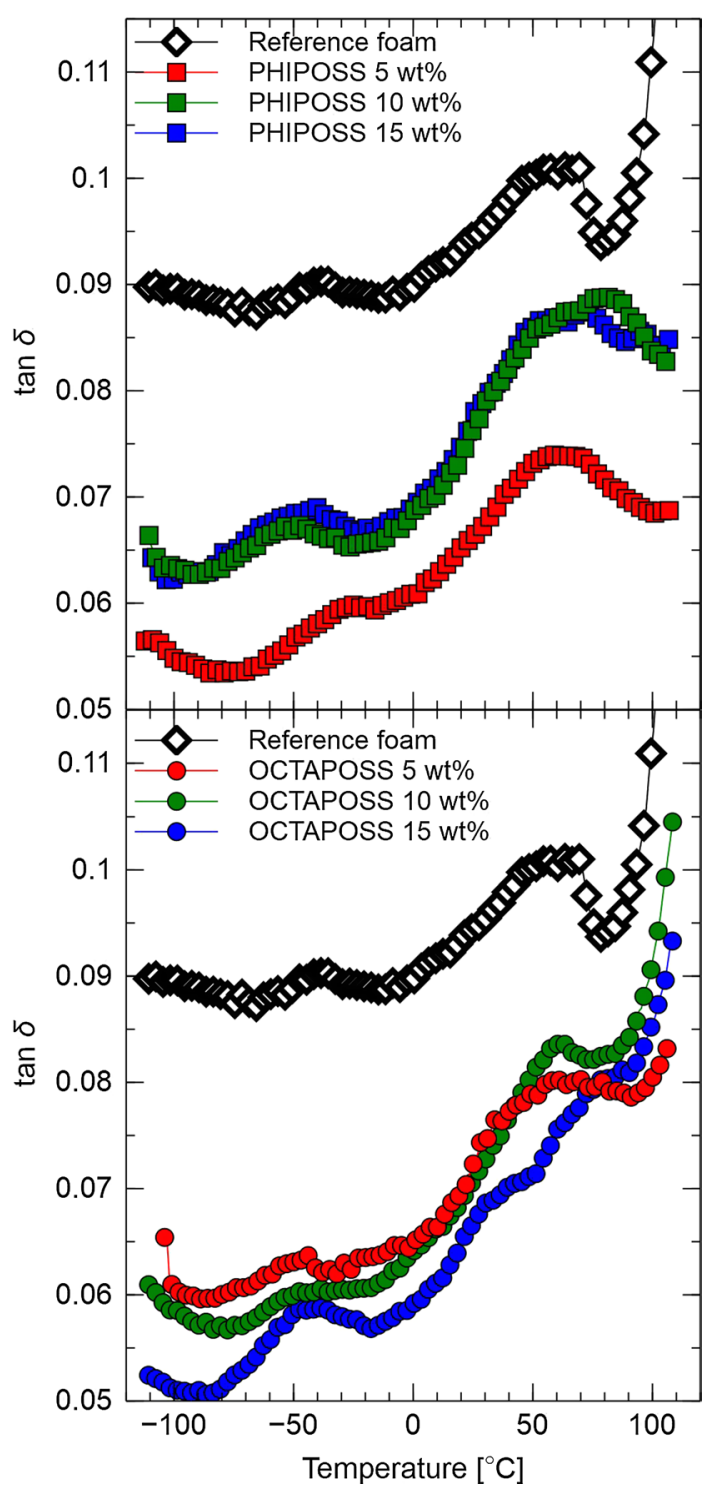

for the OCTA-POSS hybrids. The storage modulus $E^{\prime}$ (Fig. 1), initially decreases in a continuous manner with temperature, but, contrary to the expected behaviour increases again after approximately $50{ }^{\circ} \mathrm{C}$. This increase is accompanied by a significant decrease in the thickness of the sample, indicative of a mechanical collapse of the foam. Indeed, upon measurement, the sample was found irreversibly collapsed. The collapse starts at approximately the same temperature with the water evaporation peak at the first run of DSC (not shown here). It is probable that the loss of water makes the material harder and more brittle. One more factor contributing 
to the increase in the mechanical modulus at above ambient temperatures is the increase in gas pressure in the cells. The strong $\tan \delta$ peak around $80{ }^{\circ} \mathrm{C}$ is clearly related to this phenomenon, and does not seem related to a molecular relaxation as no dependence of its peak temperature is observed with changing frequency (Fig. 2). As observed in the tan $\delta$ profiles of the matrix and the composites (Fig. 3), this high-temperature peak consists of at least two components, reflecting that more than one phenomena should be taken into account. The temperature where this macromorphological change happens, as quantified by the peak temperature in the $\tan \delta$ profiles, does not change considerably with POSS type or content.

The low-temperature peak shifts to higher temperatures with increasing frequency (Fig. 2) and thus may be attributed to a molecular relaxation. At $5 \mathrm{wt} \%$ PHIPOSS (Fig. 3; Table 1), the peak migrates to higher temperatures, i.e. the relaxation becomes much slower. With further increasing PHI-POSS content, it regains its mobility and becomes faster, even compared to the reference material. On the contrary, at $5 \mathrm{wt} \%$ OCTA-POSS the relaxation is accelerated, as is peak migrates to lower temperatures, but again with increasing POSS content, the peak approaches that of the pristine material. Hence, we can observe that POSS does have an effect on the relaxation, but in a non-monotonic manner dependent on the architecture of the polymeric chains.

There is no consensus on the origin of this low-temperature peak in the literature. As mentioned in the introduction, in this area Hatakeyama et al. [11] found a step in DSC which they attributed to a low-temperature glass transition. Piszczyk et al. [24] observed in the same area a $\tan \delta$ peak in flexible foams, which they attributed to a glass transition. On the contrary, Narine et al. [18] attributed a similar peak to the $\beta$ relaxation. This is consistent with the observation that polyurethanes exhibit in this area a characteristic relaxation related to the fluctuation of the urethane bond which is typically coined as $\beta$ relaxation [21]. In the next paragraph, we will try to contribute to the clarification of the origin, based on our observations.

As we pointed out earlier, the peak temperature of the low-temperature relaxation varies considerably with POSS content in a non-monotonic manner (Fig. 3; Table 1). Sensitivity to the filler would be expected by a segmental relaxation like a glass transition. Changes in local relaxations are hardly expected and definitely not observed in PU elastomers bearing the same POSS moieties [21, 25]. On the other hand, a glass transition would have a footprint on the DSC curves, so assignment of the peak to a glass transition would not be justified. In addition, Narine et al. [18] observed a shift of the peak with different polyols. Moreover, the topology of the PU chains seems to influence the dynamics of $\beta$ relaxation of polyurethane, as proven by studies of hyperbranched polyurethanes [26-29].

In order to shed more light on this complex situation, we construct the Arrhenius map of Fig. 4, including the data from our study, traces of $\beta$ relaxations of hyperbranched PUs and elastomers, as well as the area where Piszczyk et al. [24] detected a relaxation in flexible foams. Indeed, the dynamics of $\beta$ relaxation is strongly affected by the geometry/topology of the PU chain, and it may occur at very different regions. Calculation of the activation energy by three points is not reliable; however, we can see that the slope of the traces of our materials is very similar to the one of hyperbranched systems as well as to elastomers, which 

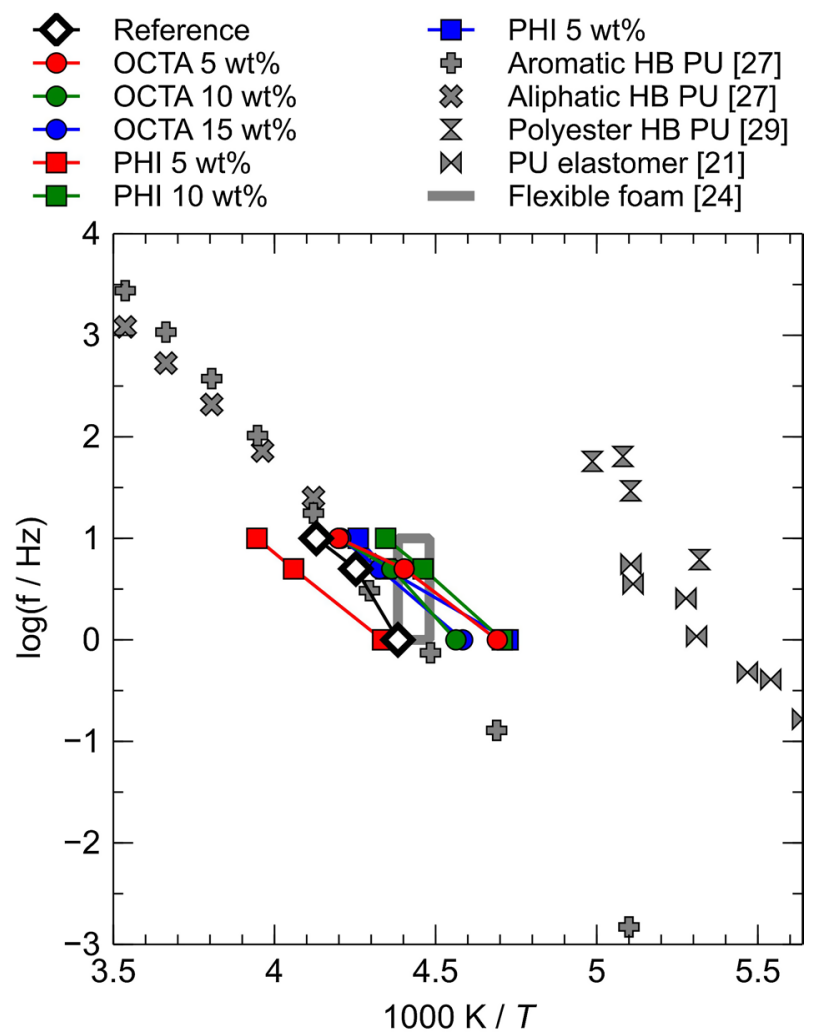

Fig. 4 Arrhenius map of the low-temperature $\tan \delta$ peak. Representative traces of the $\beta$ relaxation of PU elastomers [21] and hyperbranched (HB) PUs [27, 29], as well as the area where Piszczyk et al. [24] detected a relaxation, are also included for comparison

is another clue that the peak should be attributed to the $\beta$ relaxation. Albeit this relaxation in elastomers is not sensitive to filler content, we should keep in mind that in the foam, the environment faced by the carbonyl groups is much different than the more compact environment in elastomers, and POSS may affect it by direct interaction or indirectly, by changing the foam micromorphology. This is consistent with the much opposite effects of the crosslinking moiety (OCTAPOSS), which accelerated the relaxation, and the pendent moiety (PHI-POSS), which decelerated it. This change in micromorphology has been observed in our earlier work [8]. Finally, the dynamics of the relaxation is known to be affected by water molecules [30]. Thus, we may attribute the shift to the lower hydration level of the highly POSS-loaded hybrids. Nevertheless, a more detailed investigation would be needed for the clarification of the origin of the low-temperature relaxation.

It is not clear if the shoulder starting at $0{ }^{\circ} \mathrm{C}$ for the OCTA-POSS hybrid shifts with frequency, thus it is not easy to attribute it to a structural change or a molecular relaxation. However, bearing in mind that it has a counterpart in the DSC 
curves of the same materials, we believe it is related to a transition in the POSScrosslinked regions.

\section{Conclusions}

We studied molecular dynamics of rigid polyurethane foams reinforced with POSS moieties incorporated in two different chain architectures, i.e. as pendent groups and as crosslinks.

In the foamed PU/POSS materials, small loadings of both POSS species decelerate the chain dynamics associated with the glass transition, showing enhanced rigidity of the PU network. This is likely a result of immobilization of chains on the particles. However, further addition of POSS imposes a plasticization effect. The reasons behind this plasticization are associated with several mechanisms but the most probable ones are the disruption of the inherent crosslinking of the polyurethane, and the higher flexibility of the organic substituents of POSS as compared to the macromolecular segments of the rigid PU foam matrix.

Evidence is provided that a low-temperature mechanical relaxation is associated with the $\beta$ relaxation of polyurethane, whose behaviour seems to be very complex, but further study is needed for full understanding of its dynamics.

DSC and DMA results reveal a complex relaxation behaviour at temperatures above ambient, e.g. a strong peak in $\tan \delta$ occurs around $50{ }^{\circ} \mathrm{C}$, simultaneously with the onset of collapsing of the samples, as observed by the shift of the oscillation equilibrium point, during the experiment and from a corresponding increase in the compression modulus as cells are destroyed and their walls get in contact. Interestingly, this happens at approximately the same temperature with the water evaporation peak at the first run of DSC. It is probable that the loss of water makes the material more brittle.

Acknowledgements This project was financed by the Polish National Science Centre under contract No. DEC-2011/02/A/ST8/00409. We are grateful to prof. Polycarpos Pissis from NTUA for kind use of DSC equipment.

Open Access This article is distributed under the terms of the Creative Commons Attribution 4.0 International License (http://creativecommons.org/licenses/by/4.0/), which permits unrestricted use, distribution, and reproduction in any medium, provided you give appropriate credit to the original author(s) and the source, provide a link to the Creative Commons license, and indicate if changes were made.

\section{References}

1. Randall D, Lee S (2003) The polyurethanes book. Wiley, New York

2. Szycher M (2013) Szycher's handbook of polyurethanes. CRC Press, Boca Raton

3. Singh H, Jain AK (2008) Ignition, combustion, toxicity, and fire retardancy of polyurethane foams: a comprehensive review. J Appl Polym Sci. https://doi.org/10.1002/app.29131

4. Pielichowski K, Njuguna J, Janowski B, Pielichowski J (2006) Polyhedral oligomeric silsesquioxanes (POSS)-containing nanohybrid polymers. Adv Polym Sci 201:225-296. https://doi. org/10.1007/12_077 
5. Janowski B, Pielichowski K (2008) Thermo (oxidative) stability of novel polyurethane/POSS nanohybrid elastomers. Thermochim Acta 478:51-53. https://doi.org/10.1016/j.tca.2008.08.015

6. Janowski B, Pielichowski K (2008) Polimery nanohybrydowe zawierające poliedryczne oligosilseskwioksany. Polimery 53:87-98

7. Raftopoulos KN, Pielichowski K (2016) Segmental dynamics in hybrid polymer/POSS nanomaterials. Prog Polym Sci 52:136-187. https://doi.org/10.1016/j.progpolymsci.2015.01.003

8. Hebda E, Ozimek J, Raftopoulos KN, Michałowski S, Pielichowski J, Jancia M, Pielichowski K (2015) Synthesis and morphology of rigid polyurethane foams with POSS as pendant groups or chemical crosslinks. Polym Adv Technol. https://doi.org/10.1002/pat.3504

9. Pagacz J, Hebda E, Michałowski S, Ozimek J, Sternik D, Pielichowski K (2016) Polyurethane foams chemically reinforced with POSS - thermal degradation studies. Thermochim Acta 642:95-104. https://doi.org/10.1016/J.TCA.2016.09.006

10. Hatakeyama T, Matsumoto Y, Asano Y, Hatakeyama H (2004) Glass transition of rigid polyurethane foams derived from sodium lignosulfonate mixed with diethylene, triethylene and polyethylene glycols. Thermochim Acta 416:29-33. https://doi.org/10.1016/J.TCA.2002.12.002

11. Hatakeyama H, Matsumura H, Hatakeyama $\mathrm{T}$ (2012) Glass transition and thermal degradation of rigid polyurethane foams derived from castor oil-molasses polyols. J Therm Anal Calorim 111:1545-1552. https://doi.org/10.1007/s10973-012-2501-5

12. Thirumal M, Khastgir D, Singha NK, Manjunath BS, Naik YP (2008) Effect of foam density on the properties of water blown rigid polyurethane foam. J Appl Polym Sci 108:1810-1817. https://doi. org/10.1002/app.27712

13. Veronese VB, Menger RK, Forte MMDC, Petzhold CL (2011) Rigid polyurethane foam based on modified vegetable oil. J Appl Polym Sci 120:530-537. https://doi.org/10.1002/app.33185

14. Zhang Y, Hourston DJ (1998) Rigid interpenetrating polymer network foams prepared from a rosinbased polyurethane and an epoxy resin. J Appl Polym Sci 69:271-281. https://doi.org/10.1002/ (SICI)1097-4628(19980711)69:2\%3c271:AID-APP8\%3e3.0.CO;2-K

15. Meng X-Y, Ye L, Zhang X-G, Tang P-M, Tang J-H, Ji X, Li Z-M (2009) Effects of expandable graphite and ammonium polyphosphate on the flame-retardant and mechanical properties of rigid polyurethane foams. J Appl Polym Sci 114:853-863. https://doi.org/10.1002/app.30485

16. Abdel Hakim AA, Nassar M, Emam A, Sultan M (2011) Preparation and characterization of rigid polyurethane foam prepared from sugar-cane bagasse polyol. Mater Chem Phys 129:301-307. https ://doi.org/10.1016/J.MATCHEMPHYS.2011.04.008

17. Chen F, Lu Z (2009) Liquefaction of wheat straw and preparation of rigid polyurethane foam from the liquefaction products. J Appl Polym Sci 111:508-516. https://doi.org/10.1002/app.29107

18. Narine SS, Kong X, Bouzidi L, Sporns P (2007) Physical properties of polyurethanes produced from polyols from seed oils: II. Foams. J Am Oil Chem Soc 84:65-72. https://doi.org/10.1007/ s11746-006-1008-2

19. Pielichowski K, Hebda E, Michałowski S, Pielichowski J, Jancia M, Ozimek J (2014) The preparation method of hybrid polyurethane nanocomposite, Polish patent application No. P.408051

20. Chang L-C, Xue Y, Hsieh F-H (2001) Dynamic-mechanical study of water-blown rigid polyurethane foams with and without soy flour. J Appl Polym Sci 81:2027-2035. https://doi.org/10.1002/ app. 1635

21. Raftopoulos KN, Janowski B, Apekis L, Pissis P, Pielichowski K (2013) Direct and indirect effects of POSS on the molecular mobility of Polyurethanes with varying segment Mw. Polymer 54:27452754. https://doi.org/10.1016/j.polymer.2013.03.036

22. Raftopoulos KN, Koutsoumpis S, Jancia M, Lewicki JP, Kyriakos K, Mason HEHE, Harley SJ, Hebda E, Papadakis CM, Pielichowski K, Pissis P (2015) Reduced phase separation and slowing of dynamics in polyurethanes with three-dimensional POSS-based cross-linking moieties. Macromolecules 48:1429-1441. https://doi.org/10.1021/ma5023132

23. Raftopoulos KN, Pandis C, Apekis L, Pissis P, Janowski B, Pielichowski K, Jaczewska J (2010) Polyurethane-POSS hybrids: molecular dynamics studies. Polymer 51:709-718. https://doi. org/10.1016/j.polymer.2009.11.067

24. Piszczyk Ł, Danowska M, Mietlarek-Kropidłowska A, Szyszka M, Strankowski M (2014) Synthesis and thermal studies of flexible polyurethane nanocomposite foams obtained using nanoclay modified with flame retardant compound. J Therm Anal Calorim 118:901-909. https://doi.org/10.1007/ s10973-014-3878-0

25. Raftopoulos KN, Koutsoumpis S, Jancia M, Lewicki JP, Kyriakos K, Mason HE, Harley SJ, Hebda E, Papadakis CM, Pielichowski K, Pissis P (2015) Reduced phase separation and slowing of 
dynamics in polyurethanes with three-dimensional POSS-based cross-linking moieties. Macromolecules. https://doi.org/10.1021/ma5023132

26. Czech P, Okrasa L, Boiteux G, Mechin F, Ulanski J (2005) Polyurethane networks based on hyperbranched polyesters: synthesis and molecular relaxations. J Non Cryst Solids 351:2735-2741. https ://doi.org/10.1016/j.jnoncrysol.2005.05.038

27. Kyritsis A, Raftopoulos K, Abdel Rehim M, Said Shabaan S, Ghoneim A, Turky G, Kyritsis A, Raftopoulos K (2009) Structure and molecular dynamics of hyperbranched polymeric systems with urethane and urea linkages. Polymer 50:4039-4047. https://doi.org/10.1016/j.polymer.2009.06.037

28. Okrasa L, Zigon M, Zagar E, Czech P, Boiteux G (2005) Molecular dynamics of linear and hyperbranched polyurethanes and their blends. J Non Cryst Solids 351:2753-2758. https://doi. org/10.1016/J.JNONCRYSOL.2005.03.067

29. Czech P, Okrasa L, Méchin F, Boiteux G, Ulanski J (2006) Investigation of the polyurethane chain length influence on the molecular dynamics in networks crosslinked by hyperbranched polyester. Polymer 47:7207-7215. https://doi.org/10.1016/j.polymer.2006.05.066

30. Korzhenko A, Tabellout M, Emery JR (1999) Influence of a metal-polymer interfacial interaction on dielectric relaxation properties of polyurethane. Polymer 40:7187-7195. https://doi.org/10.1016/ S0032-3861(99)00055-5 